\title{
Study of the Microstructural Evolution of Tempered Martensite Ferritic Steel T91 upon Ultrasonic Nanocrystalline Surface Modification
}

\author{
Yinsheng He, Cheol-Woong Yang ${ }^{1}$, Je-Hyun Lee, Keesam Shin* \\ School of Nano and Advanced Materials Engineering, Changwon National University, Changwon 51140, Korea \\ ${ }^{1}$ School of Advanced Materials Science and Engineering, Sungkyunkwan University, Suwon 16419, Korea
}

*Correspondence to:

Shin K,

Tel: +82-55-213-3696

Fax: +82-55-261-7017

E-mail: keesam@changwon.ac.kr

Received July 28, 2015

Revised August 2, 2015

Accepted August 2, 2015
In this work, various electron microscopy and analysis techniques were used to investigate the microstructural evolution of a 9\% Cr tempered martensite ferritic (TMF) steel T91 upon ultrasonic nanocrystalline surface modification (UNSM) treatment. The microdimpled surface was analyzed by scanning electron microscopy. The characteristics of plastic deformation and gradient microstructure of the UNSM treated specimens were clearly revealed by crystal orientation mapping of electron backscatter diffraction (EBSD), with flexible use of the inverse pole figure, image quality, and grain boundary misorientation images. Transmission electron microscope (TEM) observation of the specimens at different depths showed the formation of dislocations, dense dislocation walls, subgrains, and grains in the lower, middle, upper, and top layers of the treated specimens. Refinement of the $\mathrm{M}_{23} \mathrm{C}_{6}$ precipitates was also observed, the size and the number density of which were found to decrease as depth from the top surface decreased. The complex microstructure and microstructural evolution of the TMF steel samples upon the UNSM treatment were well-characterized by combined use of EBSD and TEM techniques.

Key Words: Tempered martensite ferritic steel, Surface modification, Grain refinement, Electron backscatter diffraction, Transmission electron microscopy

\section{INTRODUCTION}

Materials used for fossil-fired power plants need integrated properties of creep strength and corrosion resistance under the high temperature and stress inherent to supercritical steam. Tempered martensite ferritic (TMF) $9 \%$ to $12 \% \mathrm{Cr}$ steel is one of the most commonly utilized materials for heat exchanger in power plants (Rojas et al., 2011). To provide pertinent combined properties under supercritical steam up to $650^{\circ} \mathrm{C}$, the microstructure of the materials should be composed of a ferritic matrix in martensite morphology with a large amount of phase boundaries, i.e., prior grain boundary (PAGB), lath boundary, subgrain boundary and second phase boundary (Panait et al., 2010; Rojas et al., 2011). In addition, the composition should contain high $\mathrm{Cr}$ to ensure high corrosion resistance and the precipitation of carbides (Chen et al., 2006; Shen et al., 2009; Zhong et al., 2012).

Since the beginning of the twentieth century, researchers have conducted microstructural analyses pertaining to strengthening and degradation mechanisms using optical microscope (OM), scanning electron microscope (SEM), and transmission electron microscope (TEM). Crystallographic analyses of steel under various thermal/deformation treatments have been reported by many recent researchers using electron backscatter diffraction (EBSD) of excellent spot and spatial resolution (Payton et al., 2012). Surface modification of steel

This work was supported by the National Research Foundation of Korea (NRF) grant funded by the Korea government (MSIP) (No. 2011-0030058).

(a) This is an open-access article distributed under the terms of the Creative Commons Attribution Non-Commercial License (http://creativecommons.org/licenses/by-nc/4.0) which permits unrestricted noncommercial use, distribution, and reproduction in any medium, provided the original work is properly cited.

Copyrights (C) 2015 by Korean Society of Microscopy 
is mostly performed through plastic deformation techniques in an effort to improve corrosion resistance under the critical conditions (Tan et al., 2008; Scarlin et al., 2009; Ren et al., 2010). The results of microstructural analyses of the treated specimens indicated that the grain refinement in the surface is responsible for the improvement of corrosion resistance (Ren et al., 2010). Ultrasonic nanocrystalline surface modification (UNSM) has been developed recently and applied successfully to various single phase steels (Yu et al., 2009) and alloys (Ahn et al., 2012; He et al., 2014).

In this study, TMF T91 steel, which has a ferritic matrix with various numbers of second phase precipitates dispersed in various boundaries, was subjected to UNSM treatment and analyzed. The objective of this study was to analyze the complex microstructure as well as the evolution of microstructure of T91 upon UNSM treatment. The effect of UNSM treatment on the evolution of ferrite grains and precipitates of the specimens was investigated using OM, SEM, EBSD, and TEM.

\section{MATERIALS AND METHODS}

Commercialized T91 TMF steel specimens (ASTM A213, with heat treatment consisting of austenitizing, quenching, and double tempering) with chemical composition of $0.07 \sim 0.14 \mathrm{C}$, 0.4 0.7 Mn, 0.2 0.7 Si, 8.0 9.0 Cr, 0.85 1.05 Mo, 0.18 0.25 V, $0.03 \sim 0.07 \mathrm{~N}, \sim 0.01 \mathrm{P}, \mathrm{S}$, and a balance of Fe (in wt\%) were polished (up to $\sim 1,200$ grit) then UNSM treated (Yu et al., 2009; Ahn et al., 2012) with a WC ball tip (2.4 mm in diameter) at a frequency of 20,000/s with 1,000 100,000 shot $/ \mathrm{mm}^{2}$, under static load of $60 \mathrm{~N}$, feed rate of $0.05 \mathrm{~mm} / \mathrm{rev}$, $15 \mathrm{rpm}$, and an amplitude of $30 \mu \mathrm{m}$. Sufficient coolant and lubricant were applied throughout the process.

The microstructural evolution of the untreated and treated specimens of the complex TMF steel was studied in the order of OM, SEM, EBSD, and TEM. OM and SEM analyses were carried out on the as-prepared surface and metallographically etched cross-sectional specimens using a Nikon Epiphot 200 (Nikon, Japan) and a JEM-5610 Microscope (JEOL, Japan), respectively. The etchant used in this study was Vilella's reagent $\left(100 \mathrm{~mL} \mathrm{C}_{2} \mathrm{H}_{5} \mathrm{OH}+1\right.$ g picric acid $\left.+5 \mathrm{~mL} \mathrm{HCl}\right)$. Crosssectional specimens for EBSD analysis were prepared by final polishing with colloidal silica for 2 hours. EBSD analysis was carried out on a TSL-OIM system (EDAX, USA) installed in a MIRA II LMH FE-SEM (TESCAN, Czech) using the depth beam scanning mode. TEM examination of the microstructure was carried out on the plan-view specimens at different depth (based on the OM, SEM, and EBSD analyses), whose specimens were prepared by twin jet-polishing using a solution of $95 \%$ acetic acid and 5\% perchloric acid at room temperature. To prepare TEM plan-view specimens at specific depths, the punched $3 \mathrm{~mm}$ disks were thinned from bottom by mechanical polishing to the thickness of $60 \mu \mathrm{m}$, and then back-forward jet-polished, of which the details are explained elsewhere (He et al., 2014). TEM investigation was then conducted using a JEM-2100F (JEOL) and a Philips CM200FEG (Philips, Netherlands) operated at $200 \mathrm{keV}$.

\section{RESULTS AND DISCUSSION}

\section{Scanning Electron Microscope Analysis}

Fig. 1 shows SEM images of the surfaces and cross-sections of the untreated and UNSM-treated specimens. Surface morphology was investigated by SEM (Fig. 1A and B) first in the untreated specimen, where scratches were observed because the specimen was polished before treatment. The UNSM treated specimen showed an improved surface roughness (Cherif et al., 2010) and a micro-dimpled structure (Amanov et al., 2012). The polished and etched specimens were then analyzed by using SEM, which showed that the untreated T91 has a large amount of precipitates (Fig. 1C). After UNSM treatment, it's difficult to find difference with the untreated one, nor in very high magnification observation as revealed in Fig. 1D.

It is commonly known that surface modification by various plastic deformation techniques introduces gradient strain on the surface of specimens, where the strain decreases with increasing depth from the top surface and forms a gradient (depth-dependent) microstructure. Typically, the depth of the plastic deformation (or the depth of grain refinement) on a specimen can be easily characterized by OM and SEM cross-sectional analysis (Umemoto et al., 2003; Tan et al., 2008; Yu et al., 2009), where the specimens are prepared by metallographic etching to reveal the grain boundaries. Because the microstructure of T91 steel is dominated by a large amount of precipitates dispersed in the ferritic matrix (Fig. $1 C)$, the evolution of these precipitates, i.e., reduction in size and decreased volume fraction with decreasing depth from the top surface (Zhou et al., 2008; Lu et al., 2010; Wang et al., 2011), should be observed by cross-sectional SEM analysis. However, as shown in Fig. 1D, no such evidence was found; the complex nature of T91 steel has very dense precipitates dispersed on the grain boundary, and after etching, these precipitates were revealed as opposed to the direct appearance of grain boundaries. The presence of precipitates is highly dependent on the etching process, therefore, in case of T91 (as well as other $9 \% \sim 12 \% \mathrm{Cr}$ TMF) steel, SEM is not an appropriate method of analyzing the plastic deformation features of the microstructures.

\section{Electron Backscatter Diffraction Analysis}

Fig. 2 shows the cross-sectional EBSD micrographs of the specimens before and after UNSM treatment. Fig. 2A and $B$ show the EBSD inverse pole figure (IPF) mapping and 


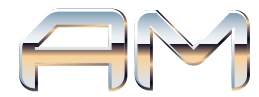

He Y et al.
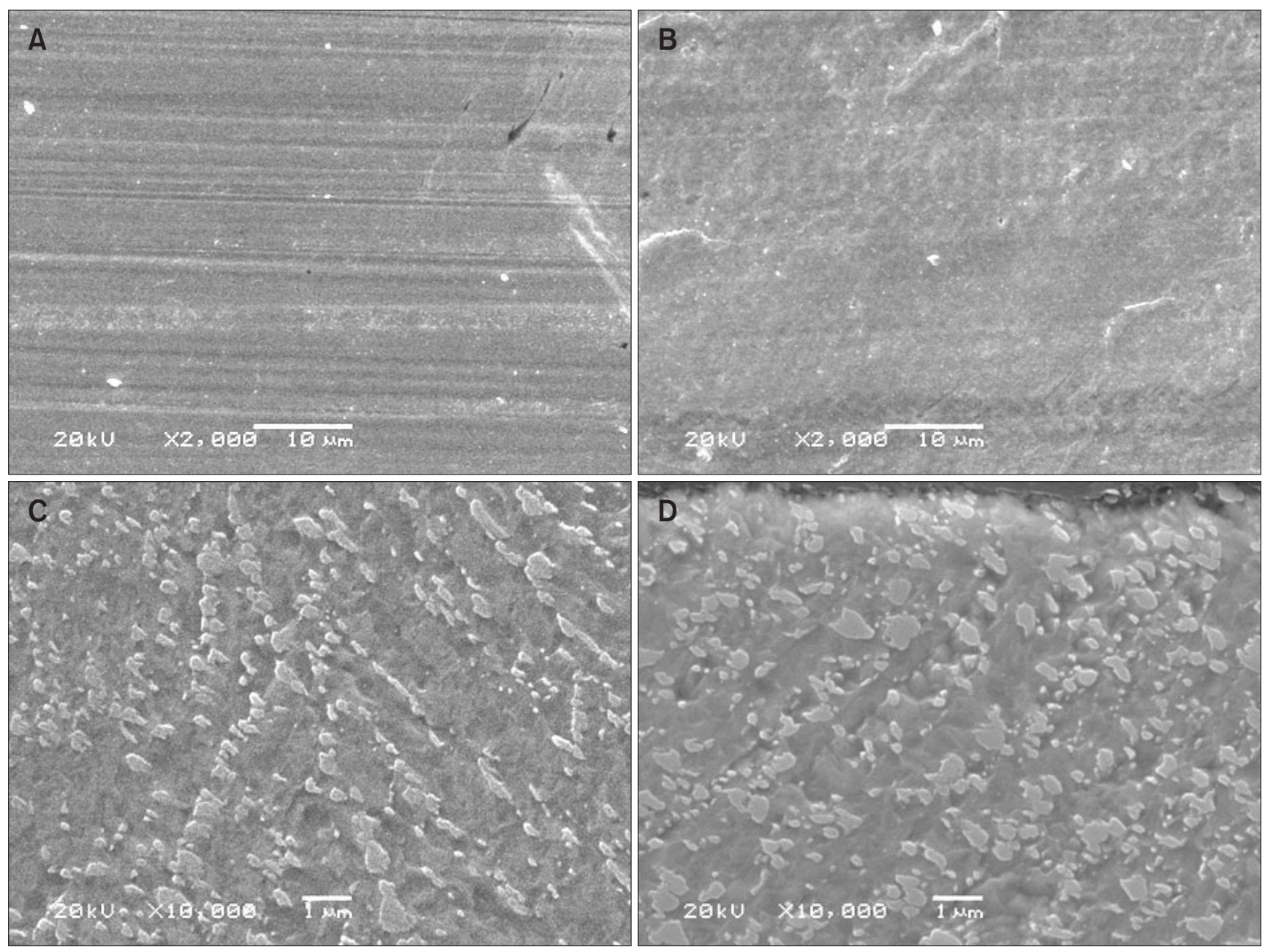

Fig. 1. Scanning electron microscope images of the untreated (A, C) and treated specimens (B, D): As prepared surface before ultrasonic nanocrystalline surface modification (UNSM) (A), after UNSM (B), cross-section of the untreated specimen (C), and cross-section after UNSM (D).

highlighted boundary $\left(2^{\circ} \sim 15^{\circ}\right.$ misorientation $)$ images. Fig. $2 \mathrm{~A} 1$ and $2 \mathrm{~B} 1$ are the image quality (IQ) mapping and highlighted boundary misorientation mapping of the untreated and treated specimens, with the low angle grain boundary (LAGB) and high angle grain boundary (HAGB) delineated in red and black, respectively. Fig. 2B, the EBSD result, clearly show the gradient microstructure on the surface region of the T91 specimen upon UNSM treatment is up to $\sim 100 \mu \mathrm{m}$ from the top treated surface (Fig. 2B). The microstructure was homogenous in untreated specimen, where complex microstructures were very clearly revealed by EBSD, i.e., PAGB, lath, subgrains, and the boundaries with low angle misorientations (Morito et al., 2006) as shown in Fig. 2A1. In the lower layer $(\sim 160 \mu \mathrm{m}$ to $\sim 100 \mu \mathrm{m})$, the microstructures of the treated and untreated samples were similar, as confirmed by the lower magnification EBSD mapping results. In the middle layer $(\sim 100 \mu \mathrm{m}$ to $\sim 60 \mu \mathrm{m})$, refinement of the lath-like grains appeared with the original grains. In the upper layer $(\sim 60 \mu \mathrm{m}$ to $\sim 30 \mu \mathrm{m})$, the refined lath-like grains were the main structure, whereas equiaxed grains are dominant structure in the top layer $(\sim 30 \mu \mathrm{m}$ to the top surface). Grain size clearly decreased with decreasing depth of the matrix, as clearly shown in Fig. 2B.

The misorientation of the grain boundaries suggests that the original coarse grains were subdivided by the formation of new grain boundaries within the matrix (Fig. 2B1). In the lower layer, the formation of new LAGB can be clearly observed; these LAGB were nucleated preferentially in original boundaries and extended to the grain interiors. In the middle layer, the LAGB meet each other to form a "grain"with a boundary comprised of the original grain boundary (especially lath boundaries) and the newly formed LAGB, preliminarily dividing the original grains into finer sized grains. In the upper and top layers, as the LAGB continued to form, the grains developed in the middle layer were further subdivided and divided into even finer sized grains.

Quantitative analyses of the fraction of LAGB in untreated and treated specimens were additionally performed using 

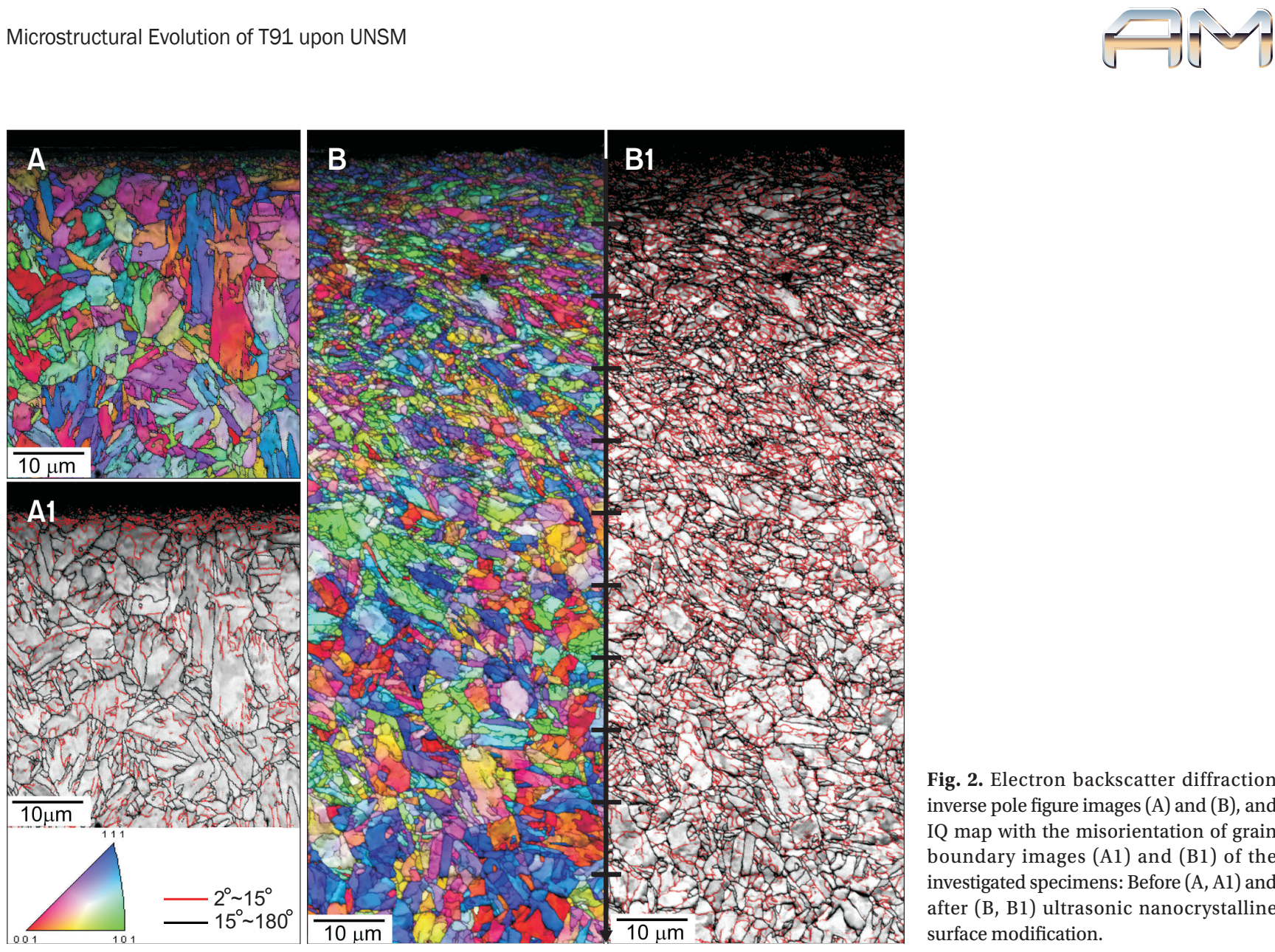

Fig. 2. Electron backscatter diffraction inverse pole figure images (A) and (B), and IQ map with the misorientation of grain boundary images (A1) and (B1) of the investigated specimens: Before (A, A1) and after $(\mathrm{B}, \mathrm{B} 1)$ ultrasonic nanocrystalline surface modification.

the orientation imaging microscopy (Fig. 3). The fraction evolution shows a parabola feature with decreased depth from the bottom of the matrix to the top surface. At deep depths of deeper than $160 \mu \mathrm{m}$, the fraction of LAGB in the treated sample is similar to the untreated sample; as depth decreased to $160 \mu \mathrm{m} \sim 60 \mu \mathrm{m}$, the LAGB increased and by $100 \%$ in the depth of around $60 \mu \mathrm{m}$. However, from there as depth neared to the top surface, the LAGB fraction decreased to almost its original value. This phenomenon further reflects the grain refinement processes described above, which were characterized by LAGB formation dividing the original grains (HAGB).

To summarize, the flexible use of IQ, IPF, and grain boundary misorientation in EBSD in this study has very aptly reflected the complex microstructures in TMF steel. The ferritic grain refinement process was the formation of dislocation in the lower layer (strain), whose pileup and accumulation lead to the formation of subgrain boundary, which increased to its highest fraction in the depth of $\sim 60 \mu \mathrm{m}$. With the further increase of strain (or decrease of depth $\sim 60 \mu \mathrm{m}$ to $\sim$ top surface), transformation of LAGB to HAGB subdivided the original grain into nanoscale, resulting in the grain refinement.

\section{Transmission Electron Microscope Analysis}

TEM analysis of the untreated and treated specimens was conducted to further study the evolution of ferrite grains
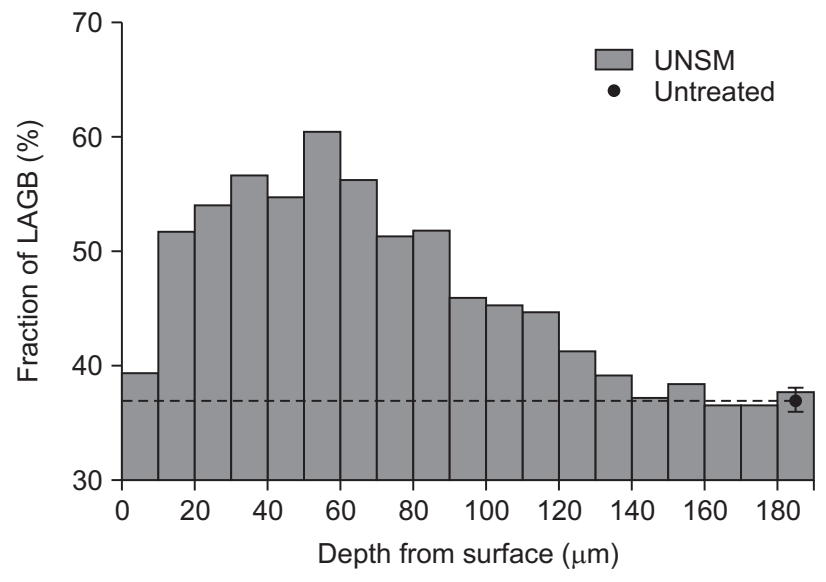

Fig. 3. Variations in low angle grain boundary (LAGB) fraction with depth from top surface of the specimens. UNSM, ultrasonic nanocrystalline surface modification.

and precipitates upon UNSM treatment. Fig. 4A is a TEM image of the specimens prior to UNSM treatment showing typical TMF microstructures (He et al., 2011), i.e., tempered martensite lath and subgrains. The main precipitate, $\mathrm{M}_{23} \mathrm{C}_{6}$ (as confirmed by selected area diffraction pattern in the inset figure), was observed in various grain boundaries (PAGB, lath boundary, subgrain) and grain interiors. The dislocation 

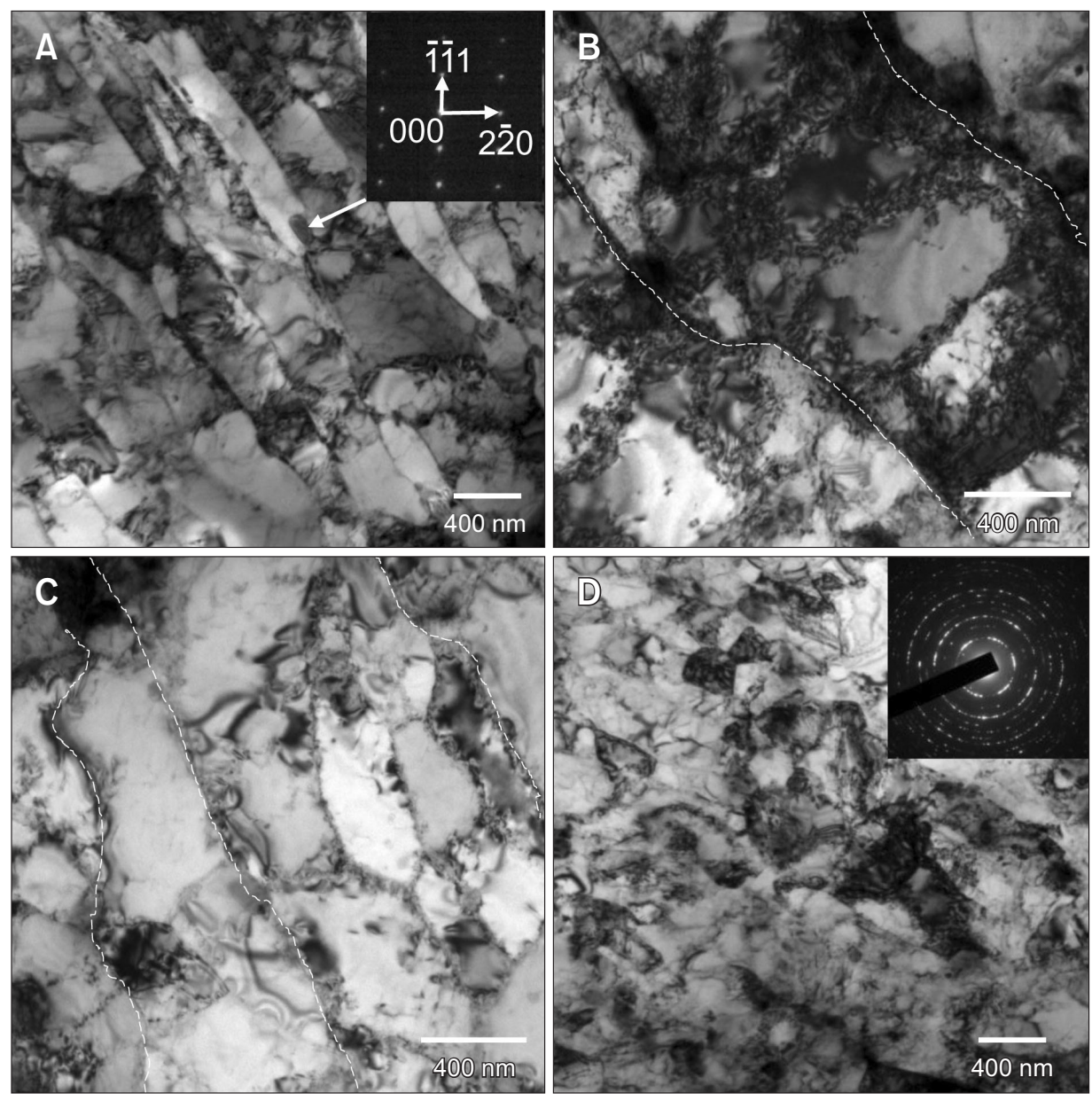

Fig. 4. Typical transmission electron microscope microstructures of specimens: Before (A) and after (B) ultrasonic nanocrystalline surface modification at depths of $\sim 100 \mu \mathrm{m}$ (B), $\sim 40 \mu \mathrm{m}$ (C), and top surface (D).

A

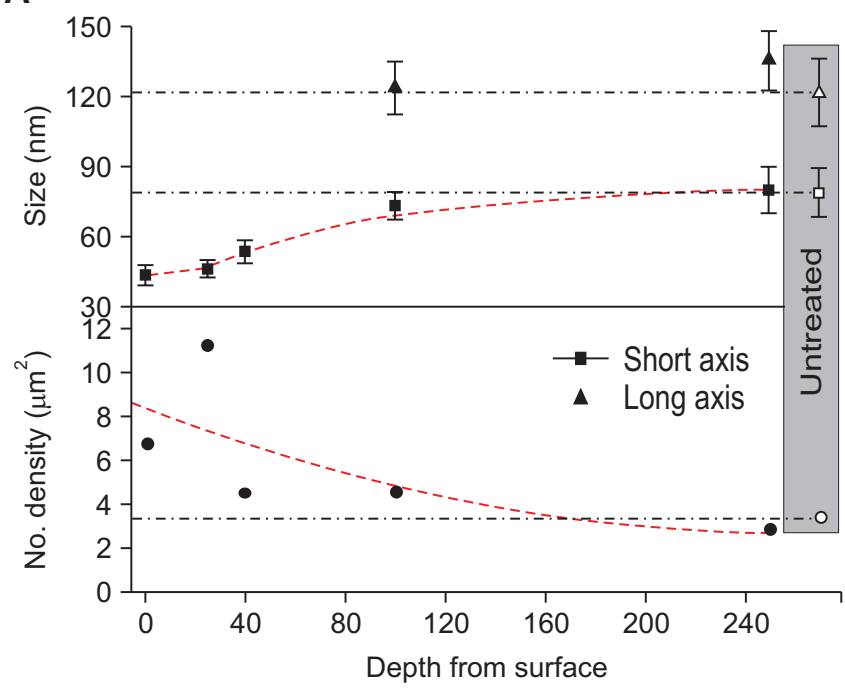

B

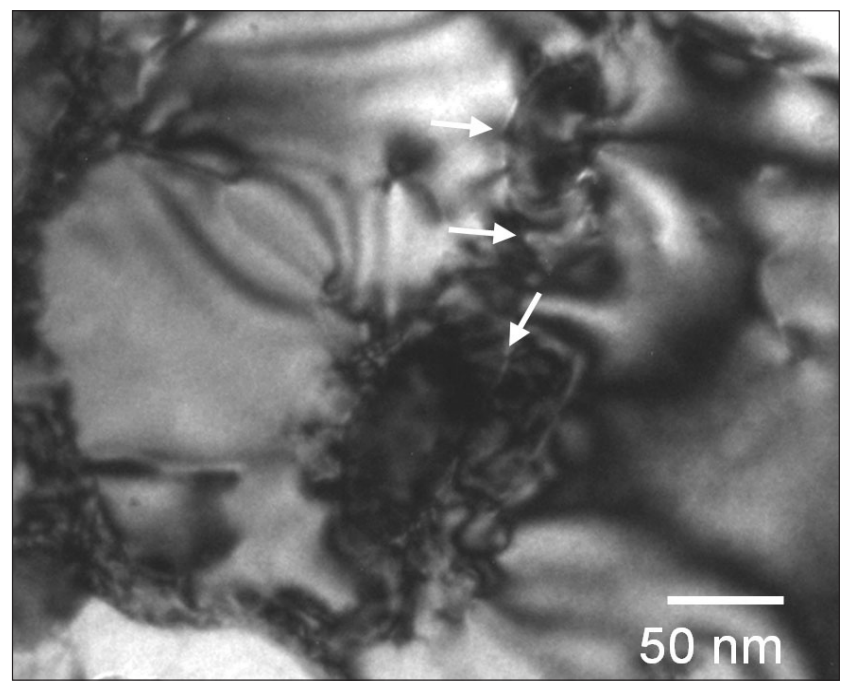

Fig. 5. (A) Variations in average size and number density of $\mathrm{M}_{23} \mathrm{C}_{6}$ with depth from the top surface. (B) A transmission electron microscope image at depth of $\sim 25 \mu \mathrm{m}$ showing $\mathrm{M}_{23} \mathrm{C}_{6}$ cut by dislocation. 
density in the untreated specimen was relatively low, due to the formation of subgrains during tempering. After UNSM treatment, the initial microstructural change was the formation of high density dislocation. The aggregation of these dislocations formed dense dislocation walls (DDWs) with low-misorientation. Fig. 4B is a TEM image of the middle layer $(\sim 100 \mu \mathrm{m}$ depth $)$, where high dislocation density was observed within the lath (marked by a white dotted line). DDWs formed preferentially vertical to the lath boundary. In the upper layer ( $40 \mu \mathrm{m}$ depth), several subgrains were formed within the lath, in accordance with EBSD results. As depth to the top surface continued to decrease, more and more nanograins ( $200 \mathrm{~nm}$ in size) was developed, as shown in Fig. 4D and the corresponding SADP, a ring-pattern.

TEM was also used to study the evolution of the $\mathrm{M}_{23} \mathrm{C}_{6}$ (average size and number density) upon UNSM treatment. The average size and number density of $\mathrm{M}_{23} \mathrm{C}_{6}$ were obtained from tens of TEM images at different magnifications of each depth. In the top layer, the size of the $\mathrm{M}_{23} \mathrm{C}_{6}$ was measured by TEM DF images, as it is difficult to distinguish the $\mathrm{M}_{23} \mathrm{C}_{6}$ from newly formed fine grain because of contrast undulation (Fig. 4D). Fig. 5A shows the evolution $\mathrm{M}_{23} \mathrm{C}_{6}$ at various depths from the top surface. The size of the $\mathrm{M}_{23} \mathrm{C}_{6}$ decreased with decrease of depth from the top surface, indicating that $\mathrm{M}_{23} \mathrm{C}_{6}$ was refined by the UNSM treatment. Fig. $5 \mathrm{~A}$, the number density of $\mathrm{M}_{23} \mathrm{C}_{6}$ as function of depth, indicates that the number density decreases toward its original value as depth increased from the top surface to deep matrix. Although the data shows some fluctuations between the upper layer and the top surface, the number did clearly increase in the top layer. Reduction of size in the lower and middle layers occurred likely due to the compression of $\mathrm{M}_{23} \mathrm{C}_{6}$ after the introduction of strain by plastic deformation. Under high strain in the upper and top layer, further reduction in size occurred where one coarse $\mathrm{M}_{23} \mathrm{C}_{6}$ was cut by dislocation and slid into two $\mathrm{M}_{23} \mathrm{C}_{6}$, as shown in the TEM image of Fig. 5B (taken at depth of $\sim 25 \mu \mathrm{m}$ ). The same phenomenon was potentially the cause of the increase in numerical density in the high strain layer, especially the upper and top layers.

In summary, the evolution of the complex TMF matrix structure and $\mathrm{M}_{23} \mathrm{C}_{6}$ were characterized successfully by the combined use of EBSD and TEM in this study, including the effects of second phase/precipitates on the refinement of ferritic grains.

\section{SUMIMARY}

In this study, various electron microscopes and analysis techniques were used to study the microstructural evolution of a 9\% Cr TMF T91 steel upon UNSM treatment. The conclusions of this study can be summarized as follows.

(1) SEM results show an improved surface roughness as the micro-dimpling surface was formed in UNSM treated specimen.

(2) EBSD analysis of the cross-sectional specimen clearly shows the plastic deformation and the gradient microstructure from the top surface to the deep matrix in the treated specimen. IQ and grain boundary misorientation images show a parabolic evolution of LAGB as the depth decreases from the top surface, that i) increase of LAGB with the decrease of depth from $\sim 160 \mu \mathrm{m}$ to $\sim 60 \mu \mathrm{m}$ and ii) decrease from $\sim 60 \mu \mathrm{m}$ to top surface.

(3) TEM analysis shows the refinement of ferritic grain and $\mathrm{M}_{23} \mathrm{C}_{6}$. High dislocation density was observed in the lower layer, then as depth to the top surface decreased, DDWs and subgrains were observed in the treated specimens. The average size decreased and number density of $\mathrm{M}_{23} \mathrm{C}_{6}$ increased, respectively, as depth decreased.

This study confirmed that microstructural refinement of T91 upon UNSM treatment is accomplished on the ferritic matrix through deformation induced dislocations evolution to DDWs with low-angle misorientation, followed by subgrains formation and high angle grain boundaries causing refinement of grains. And the precipitates, with deformation induced dislocation cut through $\mathrm{M}_{23} \mathrm{C}_{6}$ resulted in reduction in size and increase in number density.

\section{CONFLICT OF INTEREST}

No potential conflict of interest relevant to this article was reported.

\section{REFERENCES}

Ahn D, He Y, Wan Z, Cho I S, Lee C S, Park I G, Pyoun Y S, Dong J, and Shin K (2012) Effect of ultrasonic nano-crystalline surface modification on the microstructural evolution and mechanical properties of Al5052 alloy. Surf. Interface Anal. 44, 1415-1417.

Amanov A, Cho I S, Pyoun Y S, Lee C S, and Park I G (2012) Microdimpled surface by ultrasonic nanocrystal surface modification and its tribological effects. Wear 286-287, 136-144.

Chen Y, Sridharan K, and Allen T (2006) Corrosion behavior of ferriticmartensitic steel T91 in supercritical water. Corros. Sci. 48, 28432854.

Cherif A, Pyoun Y, and Scholtes B (2010) Effects of ultrasonic nanocrystal 
surface modification (UNSM) on residual stress state and fatigue strength of AISI 304. J. Mater. Eng. Perform. 19, 282-286.

He Y, Chang J, Dong J, and Shin K (2011) Microstructural evolution of X20CrMoV12.1 steel upon long-term on-site exposure in power plants. Adv. Sci. Lett. 4, 1416-1423.

He Y, Li K, Pyoun Y S, Cho I S, Lee C S, Park I G, Song J I, Yang C W, Lee $\mathrm{J} \mathrm{H}$, and Shin K (2014) Characterization of the nano-scale surface layer of a tempered martensitic steel synthesized by ultrasonic nanocrystalline surface modification treatment. Sci. Adv. Mater. 6, 2260-2268.

Lu S, Wang Z, and Lu K (2010) Strain-induced microstructure refinement in a tool steel subjected to surface mechanical attrition treatment. J. Mater. Sci. Technol. 26, 258-263.

Morito S, Huang X, Furuhara T, Maki T, and Hansen N (2006) The morphology and crystallography of lath martensite in alloy steels. Acta Mater. 54, 5323-5331.

Panait C G, Zielińska-Lipiec A, Koziel T, Czyrska-Filemonowicz A, GourguesLorenzon A F, and Bendick W (2010) Evolution of dislocation density, size of subgrains and MX-type precipitates in a P91 steel during creep and during thermal ageing at $600 \mathrm{oC}$ for more than $100,000 \mathrm{~h}$. Mater. Sci. Eng. A 527, 4062-4069.

Payton E J, Aghajani A, Otto F, Eggeler G, and Yardley V A (2012) On the nature of internal interfaces in a tempered martensite ferritic steel and their evolution during long-term creep. Scripta. Mater. 66, 10451048.

Ren X, Sridharan K, and Allen T R (2010) Effect of grain refinement on corrosion of ferritic-martensitic steels in supercritical water environment. Mater. Corros. 61, 748-755.
Rojas D, Garcia J, Prat O, Sauthoff G, and Kaysser-Pyzalla A R (2011) $9 \% \mathrm{Cr}$ heat resistant steels: Alloy design, microstructure evolution and creep response at $650^{\circ} \mathrm{C}$. Mater. Sci. Eng. A 528, 5164-5176.

Scarlin R B, Knoedler R, and Straub S (2009) Method for the surface treatment of ferritic/martensitic 9-12\% Cr steel. United States Patent: US 7,568,368 B2.

Shen Y Z, Kim S H, Cho H D, Han C H, and Ryu W S (2009) Precipitate phases of a ferritic/martensitic $9 \% \mathrm{Cr}$ steel for nuclear power reactors. Nucl. Eng. Des. 239, 648-654.

Tan L, Ren X, Sridharan K, and Allen T R (2008) Effect of shot-peening on the oxidation of alloy $800 \mathrm{H}$ exposed to supercritical water and cyclic oxidation. Corros. Sci. 50, 2040-2046.

Umemoto M, Todaka Y, and Tsuchiya K (2003) Formation of nanocrystalline structure in steels by air blast shot peening. Meter. Trans. 44, 1488-1493.

Wang L M, Wang Z B, and Lu K (2011) Grain size effects on the austenitization process in a nanostructured ferritic steel. Acta Mater. 59, 3710-3719.

Yu H, Dong J L, Yoo D H, Shin K, Jung J S, Pyoun Y, and Cho I (2009) Effect of ultrasonic and air blast shot peening on the microstructural evolution and michanical properties of SUS304. Korean Phys. Soc. 54, 1161-1166.

Zhong X Y, Wu X Q, and Han E H (2012) The characteristic of oxide scales on T91 tube after long-term service in an ultra-supercritical coal power plant. J. Supercrit. Fluids 72, 68-77.

Zhou L, Liu G, Ma X L, and Lu K (2008) Strain-induced refinement in a steel with spheroidal cementite subjected to surface mechanical attrition treatment. Acta Mater. 56, 78-87. 